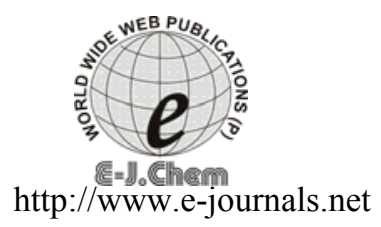

ISSN: 0973-4945; CODEN ECJHAO

E-Journal of Chemistry

2011, 8(S1), S377-S391

\title{
Removal of Copper (II) Ions from Aqueous Solutions by Adsorption with Low Cost Acid Activated Cynodon Dactylon Carbon
}

\author{
U. GAYATHRI, B.R. VENKATRAMAN ${ }^{*}$ and S. ARIVOLI ${ }^{\S}$
}

\author{
Department of Chemistry \\ Sengamala Thayaar Educational Trust Women's College \\ Sundarakkottai, Mannargudi-614 001, Tamilnadu, India \\ *P.G Department of Chemistry \\ Periyar E.V.R.College(Autonomous) \\ Trichy-620023, Tamil Nadu, India \\ ${ }^{\S}$ Department of Chemistry \\ Thiru.Vi.Ka.College, Thiruvarur, Tamilnadu, India \\ brvenkatraman@yahoo.com
}

Received 27 January 2011; Revised 14 May 2011; Accepted 5 June 2011

\begin{abstract}
The main purpose of this work was to exploit low cost and efficient sorbents for the removal of copper from aqueous solution using Cynodon dactylon carbon. It was observed from the experimental results that almost $90-100 \%$ copper can be removed from the aqueous solution. Adsorption kinetics and equilibrium have been investigated as a function of initial copper ion concentration. $\mathrm{pH}$, contact time and adsorbent dosage. Kinetics studies suggested that the adsorption allowed first order reaction. Equilibrium data were analyzed using Langmuir and Freundlich isotherm models. On the basis of experimental results and the model parameters, it can be concluded that the carbonaceous Cynodon dactylon is effective for the removal of copper ion from aqueous solution.
\end{abstract}

Keywords: Adsorption isotherm, Adsorption kinetics, Activated Cynodon dactylon bark carbon (CBC), Intra particle diffusion, Regeneration pattern

\section{Introduction}

Although some trace metals are considered as essential plant nutrients. Most heavy metals are of considerable health and environmental concern because of their toxicity and bio accumulative behavior ${ }^{1-3} \cdot \mathrm{Pb}^{2+}, \mathrm{Cu}^{2+}, \mathrm{Fe}^{3+}$ and $\mathrm{Cr}^{3+}$ are especially common metals that tend to accumulate in organisms, causing numerous diseases and disorders ${ }^{4}$. They are also common ground water contaminants at industrial and military installation. Numerous processes exist for removing dissolved heavy metals, including ion exchange, precipitation, phyto extraction, 
ultrafiltration, reverse osmosis and electro dialysis ${ }^{5-8}$. The use of alternative low cost materials as sorbents for the removal of heavy metals has been emphasized recently. Activated carbon adsorption is considered to be a particularly competitive and effective process for the removal of heavy metals at trace quantities 9 . The present study was undertaken to evaluate the efficiency of a carbon adsorbent prepared from acid activated Cynodon dactylon carbon for the removal of copper(II) ions in aqueous solution. The effects of parameters such as initial copper ion concentration, $\mathrm{pH}$, adsorbent dosages, contact time, other ions and temperature were studied by using Batch technique. In this paper, we have reported the applicability of kinetic and mass transfer models for the adsorption of $\mathrm{Cu}(\mathrm{II})$ ion onto acid activated Cynodon dactylon carbon.

\section{Experimental}

All the chemicals used were supplied by SD fine chemicals with high purity. Cynodon dactylon was treated with conc. Sulphuric acid in a weight ratio $1: 1$, to increase the adsorption property of the adsorbent. The resulting mixture was kept in a furnace maintained at $600{ }^{\circ} \mathrm{C}$ for $12 \mathrm{~h}$. After this, the contents were extensively washed with doubly distilled water to remove excess acid and filtered through a Whatman filter paper. Then it was dried for $5 \mathrm{~h}$ at $120 \pm 5^{\circ} \mathrm{C}$. By a sieving process, the carbon product as ground and the portion retained between 0.022- $0.025 \mathrm{~mm}$ sieves were separated and stored in a Pyrex glass bottle.

\section{Method}

\section{Adsorption batch process}

The adsorption experiments were carried out in a batch process at $35,40,45$ and $50{ }^{\circ} \mathrm{C}$ temperatures. The known weight adsorbent material was added to $50 \mathrm{~mL}$ of the metal ion solutions with an initial concentration of $10-100 \mathrm{mg} / \mathrm{L}$. The contents were shaken thoroughly using a mechanical shaker rotating with a speed of $120 \mathrm{rpm}$. The solution was then filtered at preset time intervals and the residual concentration of copper ion was measures by UV - Visible spectrophotometers.

\section{Effect of Variable parameters}

\section{Effect of adsorbent dose}

The various doses of the adsorbents are mixed with the concentration of $30 \mathrm{mg} / \mathrm{L}$ of copper ion and the mixture was agitated in a mechanical shaker. From 10 to $100 \mathrm{mg} / 50 \mathrm{~mL}$ of the adsorbent doses was taken and the percentage of adsorption was determined by keeping all other factors constant.

\section{Initial concentration of copper ion}

Adsorption experiments were conducted with different initial concentration of copper ions ranging from 10 to $60 \mathrm{mg} / \mathrm{L}$ and other factors were kept constant. From this, rate of adsorption was determined.

\section{Contact time}

While keeping particle size, initial concentration, dosage, $\mathrm{pH}$ and temperature constant, the removal of the copper ions in a single cycle was determined by the effect of contact between adsorbent and adsorbate.

\section{Initial $\mathrm{pH}$}

While carrying out the experiments particle size of the adsorbent, temperature and other factors kept constant and the adsorption process were carried out at a range of $\mathrm{pH}$ of the solution 3 to 10 . The required amounts of hydrochloric acid and sodium hydroxide solutions were added to maintain the acidic and alkaline $\mathrm{pH}$ of the medium. 


\section{Other ions}

The experiments were done in the presence of chloride and calcium ions were verified using the adsorbents. While doing the determination of the percentage of metal ion was taken as $30 \mathrm{mg} / \mathrm{L}$ with varying the concentration of the other ions were added and all other factors kept constant.

\section{Temperature}

In a thermostated shaker machine, (Remi, India) four different temperatures like 35, 40, 45 and $50{ }^{\circ} \mathrm{C}$ were performed during the adsorption experiments. The results were used to investigate the thermodynamics of the adsorption process.

\section{Zero point charge}

$\mathrm{pH}$ drift method was used to measure the $\mathrm{pH}$ at the potential of zero charge of the carbon $\left(\mathrm{pH}_{\mathrm{zpc}}\right)^{10} .50 \mathrm{mg}$ of the activated carbon was added to $50 \mathrm{~mL}$ of the solution. After stabilization the final $\mathrm{pH}$ was recorded. The $\mathrm{pH}$ of the solution was adjusted by using $0.01 \mathrm{M}$ sodium hydroxide or hydrochloric acid. Nitrogen was bubbled through the solution at $25{ }^{\circ} \mathrm{C}$ to remove the dissolved carbon dioxide. The zero point charge of the activated carbon was determined by plotting the graph between final $\mathrm{pH}$ valued versus initial $\mathrm{pH}$ values ${ }^{10}$.

\section{Titration studies}

While doing the titration with sodium carbonate and sodium hydroxide, strong acidic carboxylic groups neutralized sodium carbonate and weakly acidic phenolic groups neutralized sodium hydroxide. From this, strong acidic carboxylic acid groups are thought to be lactones, lactol and carboxyl group and weakly acidic phenolic groups are present in it. Therefore, by selective neutralization using bases of different strength, the surface acidic functional group in carbon can be characterized both quantitatively and qualitatively. Neutralization with hydrochloric acid characterized pyrones and chromones are present. The basic properties have described to surface basic groups and the pi electron system of carbon basal planes. From the results that indicate the activated carbon used may possess acidic oxygen functional group on their surface and this is supported well by their respective zero point charge values. The results were represented in Table 1.

\section{Reformation studies}

Reformation of the adsorbed carbon is done by using $0.1 \mathrm{M}$ mineral acids and sodium chloride solutions.

\section{Analytical measurements}

Before and after adsorption of the adsorbents were recorded at the CECRI, Karaikudi, South India. FT-IR, XRD patterns and SEM images were measured.

\section{Results and Discussion}

\section{Physicochemical properties of the adsorbent}

Activated carbons are a wide used adsorbent due to its specific high adsorption capacity, high surface area, micro porous structure and high surface area, high degree of surface, specific surface area, high chemical nature and pore structure usually determines the sorption activity. The physicochemical properties of the Cynodon dactylon carbon adsorbent are given in Table 1 .

\section{Effect of adsorbent dosage}

The adsorption of adsorbate on adsorbent was studied by changing the adsorbent $(10-100 \mathrm{mg} / 50 \mathrm{~mL}$ ) for adsorbate concentration of $30 \mathrm{mg} / \mathrm{L}$ (Figure 1). If the dosage of adsorbent increase the percentage of adsorption of adsorbate also increases and then the surface area of the adsorbent increases and availability of more adsorption sites were produced $^{11-13}$. For entire adsorption studies $25 \mathrm{mg} / 50 \mathrm{~mL}$ of dosage of adsorbent is enough. 
Table 1. Physical and chemical composition of the Cynodon dactylon adsorbent

\begin{tabular}{cc}
\hline Properties & CBC \\
\hline Particle size, mm & 0.025 \\
Density, g/cc & 0.1528 \\
Moisture content, \% & 0.98 \\
Loss on ignition, \% & 82 \\
Acid insoluble matter, \% & 3.2 \\
Water soluble matter, \% & 0.39 \\
pH of aqueous solution & 6.3 \\
pH zpc & 5.4 \\
Surface groups (m equiv/g) & \\
Carboxylic acid & 0.325 \\
Lactone, lactol & 0.074 \\
Phenolic & 0.067 \\
Basic (pyrones and chromenes) & 0.026 \\
\hline
\end{tabular}

Table 2. Equilibrium parameters for the adsorption of copper ion by $\mathrm{CBC}$

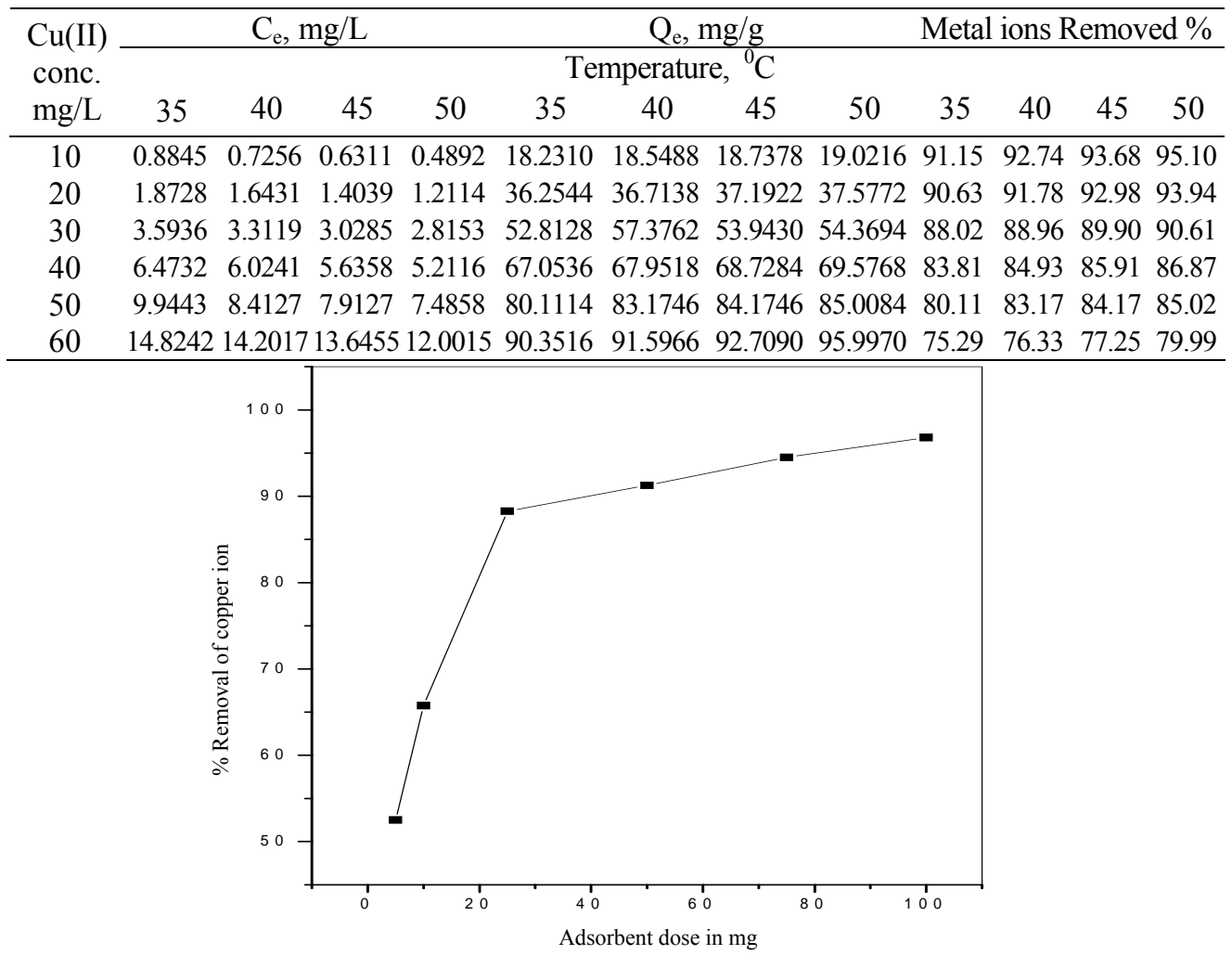

Figure 1. Effect of adsorbent dose on the removal of copper ion by $\mathrm{CBC}[\mathrm{Cu}]=30 \mathrm{mg} / \mathrm{L}$; temp $=35^{\circ} \mathrm{C}$; contact time $=60 \mathrm{~min} \mathrm{pH}=6.3$

\section{Effect of agitation time and initial adsorbate concentration}

The kinetics of adsorption of copper ion by Cynodon dactylon is shown in Figure $2 \&$ Table 2 with smooth and single plots indicating mono layer adsorption of metal ion on the carbon ${ }^{14}$. 
The removal of copper ion increases with the lapse time and attains equilibrium in 40 minutes for all concentrations. With increase in metal ion concentration from 10 to $60 \mathrm{mg} / \mathrm{L}$, the amount of copper ion adsorbed increases while the percent removal decreases, indicated that the metal ion removal by adsorption dependent.

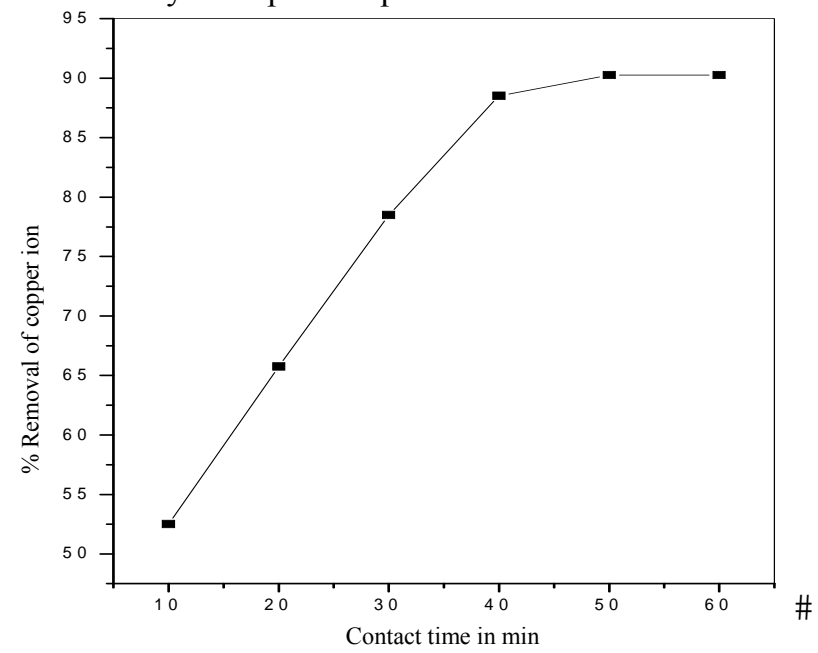

Figure 2. Effect of contact time on the adsorpton of copper ion by $\mathrm{CBC}[\mathrm{Cu}]=30 \mathrm{mg} / \mathrm{L}$; adsorbent dose $=25 \mathrm{mg} / 50 \mathrm{~mL}$; temp $=35^{\circ} \mathrm{C}$

\section{Sorption isotherms}

The sorption data have been subjected to different sorption isotherms, namely, Langmuir, Freundlich and dubinin - kaganer - radhushkevich (DKR). The equilibrium data for metal ions over the concentration range from 10 to $60 \mathrm{mg} / \mathrm{L}$ at $35,40,45$ and $50{ }^{\circ} \mathrm{C}$ have been correlated with the Langmuir isotherm ${ }^{15}$.

$$
\mathrm{C}_{\mathrm{e}} / \mathrm{Q}_{\mathrm{e}}=1 / \mathrm{Q}_{\mathrm{m}} \mathrm{b}+\mathrm{C}_{\mathrm{e}} / \mathrm{Q}_{\mathrm{m}}
$$

Where $C_{e}$ is the equilibrium concentration of metal ion solution $(\mathrm{mL}), \mathrm{Q}_{\mathrm{e}}$ is the amount adsorbed at equilibrium $(\mathrm{mg} / \mathrm{g})$ and $\mathrm{Q}_{\mathrm{m}}$ and $\mathrm{b}$ are Langmuir constants related to sorption capacity and sorption energy respectively. Maxmium sorption capacity $\left(\mathrm{Q}_{\mathrm{m}}\right)$ represents monolayer coverage of the sorbent with sorbate and $\mathrm{b}$ represents enthalpy of sorption and should change with temperature ${ }^{16,17}$. A linear plot is obtained from $\mathrm{C}_{\mathrm{e}} / \mathrm{Q}_{\mathrm{e}}$ is plotted against $\mathrm{C}_{\mathrm{e}}$ over the entire concentration range of metal ions investigated. The Langmuir model parameters and the statistical fits of the sorption data to this equation are given in Table 3 and Figure 3. Further it confirms that the endothermic nature of the process involved in the system. To confirm the adorability of the adsorption process the separation factor $\left(R_{L}\right)$ has calculated and presented in Table 4 . The equilibrium parameter $R_{L}$, which is defined as

$$
\mathrm{R}_{\mathrm{L}}+1 /(1+\mathrm{b}(\mathrm{A})
$$

Table 3. Langmuir isotherm results for the adsorption of copper ion by $\mathrm{CBC}$

\begin{tabular}{cccc}
\hline Temperature & \multicolumn{3}{c}{ Statistical parameters / constants } \\
\hline${ }^{\circ} \mathrm{C}$ & $\mathrm{r}^{2}$ & $\mathrm{Q}_{\mathrm{m}}$ & $\mathrm{b}$ \\
35 & 0.9998 & 117.51 & 0.2199 \\
40 & 0.9977 & 115.34 & 0.2758 \\
45 & 0.9976 & 114.67 & 0.3095 \\
50 & 0.9955 & 116.68 & 0.3508 \\
\hline
\end{tabular}




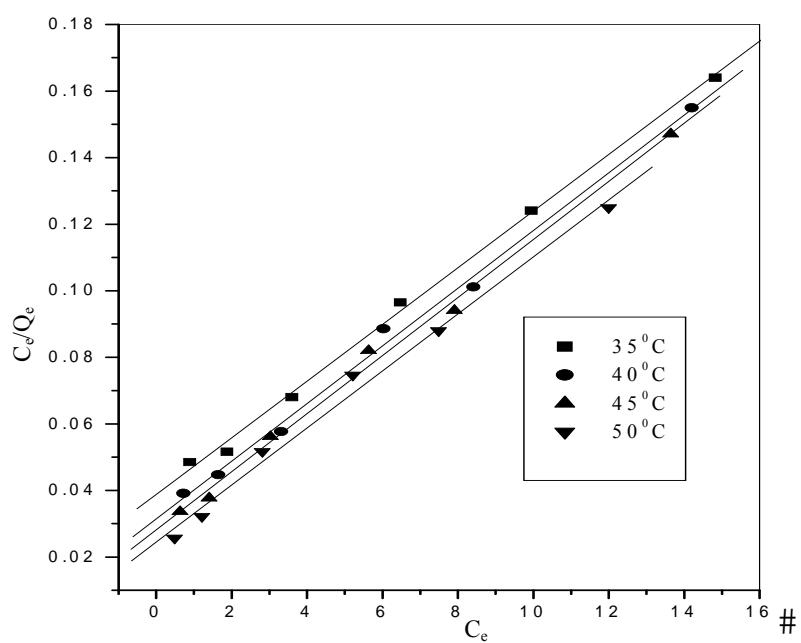

Figure 3. Liner Langmiur adsorption isotherm for copper ion

In the range of $0<\mathrm{R}_{\mathrm{L}}<1$ reflects the favorable adsorption process ${ }^{18,19}$. In the present investigation the equilibrium parameter was found to be in the range $0<\mathrm{R}_{\mathrm{L}}<1$ which is shown in Table 4 . This indicated to the fact that the sorption process was very favorable and the adsorbent employed exhibited a good potential ${ }^{18}$.

Table 4. Dimensionless Separation factor $\left(\mathrm{R}_{\mathrm{L}}\right)$ for the adsorption of copper ion by $\mathrm{CBC}$

\begin{tabular}{ccccc}
\hline $\begin{array}{c}\text { Copper ion } \\
\text { concentration, mg/L }\end{array}$ & 35 & Temperature, ${ }^{\circ} \mathrm{C}$ \\
\hline 10 & 0.313 & 0.263 & 0.243 & 0.222 \\
20 & 0.185 & 0.151 & 0.138 & 0.125 \\
30 & 0.136 & 0.106 & 0.097 & 0.086 \\
40 & 0.102 & 0.081 & 0.074 & 0.066 \\
50 & 0.083 & 0.066 & 0.060 & 0.054 \\
60 & 0.070 & 0.056 & 0.051 & 0.045 \\
\hline
\end{tabular}

The Freundlich sorption isotherm, one of the most widely used mathematical descriptions, usually fit the experimental data over a wide range of concentrations. This isotherm gives an expression encompassing the surface heterogeneity and the exponential distribution of active sites and their energies. The Freundlich equation has also been employed for the adsorption of copper ion on the adsorbent. The Freundlich isotherm have represented as

$$
\log \mathrm{Q}_{\mathrm{e}}=\log \mathrm{K}_{\mathrm{f}}+1 / \mathrm{n} \log \mathrm{C}_{\mathrm{e}}
$$

Where $C_{e}$ is the equilibrium concentration of metal ion in solution $(\mathrm{mg} / \mathrm{L})$ and $\mathrm{Q}_{\mathrm{e}}$ is the amount of copper ion adsorbed $\mathrm{mg} / \mathrm{g}$ and the constants $\mathrm{K}_{\mathrm{f}}$ and $\mathrm{n}$ were calculated and given in Table 5 and Figure $4 . K_{f}$ is a parameter related to the temperature and $n$ is a characteristic constant for the adsorption system under study. Linear plot of $\log \mathrm{Q}_{\mathrm{e}}$ versus $C_{e}$ shows that the adsorption of copper ion follows the Freundlich isotherm, (Figure 4). The values clearly show that dominance in adsorption capacity. The intensity of adsorption is an indication of the bond energies between copper ion and adsorbent and the possibility of slight chemisorptions rather than physisorption ${ }^{17-19}$. The values of $\mathrm{n}$ is greater than one indicating the adsorption is much more favorable ${ }^{20,21}$. The possibility of multilayer adsorption of copper ion through percolation process cannot be ruled out. Values of $\mathrm{n}$ between 2 and 10 shows good adsorption, that means multilayer adsorption on the surface is possible ${ }^{22}$. 
Table 5. Freundlich isotherm results for the adsorption of copper ion by CBC

\begin{tabular}{cccc}
\hline Temperature & \multicolumn{3}{c}{ Statistical parameters / constants } \\
\hline${ }^{\circ} \mathrm{C}$ & $\mathrm{r}^{2}$ & $\mathrm{~K}_{\mathrm{f}}$ & $\mathrm{n}$ \\
35 & 0.9799 & 1.7358 & 1.8132 \\
40 & 0.9770 & 1.7057 & 1.8726 \\
45 & 0.9870 & 1.6733 & 2.0088 \\
\hline 50 & 0.9890 & 1.6450 & \\
\hline
\end{tabular}

Figure 4. Liner Freundlich adsorption isotherm for copper ion

\section{Sorption kinetics}

Several steps can be used to illustrate the adsorption mechanism. To investigate the mechanism of metal ion adsorption and the potential rate controlling steps, such as diffusion mass transport and chemical reaction processes, it is necessary to characterize the main adsorption mechanisms ${ }^{23}$. Numerous sorption systems have been reported as fist order kinetic processes ${ }^{24}$. In the present study the kinetics of the copper ion removal has carried out to understand the behavior of cynodon dactylon adsorbent. The adsorption of copper ion from an aqueous solution follows reversible first order kinetics, when a single species considered on a heterogeneous surface. The first order rate expression of Lagergran ${ }^{25}$ can be expressed as

$$
\log \left(\mathrm{q}_{\mathrm{e}}-\mathrm{q}_{\mathrm{t}}\right)+\mathrm{Kt} / 2.303+\log \mathrm{q}_{\mathrm{e}}
$$

Where $\mathrm{q}_{\mathrm{e}}$ and $\mathrm{q}_{\mathrm{t}}$ are the amount $\left(\mathrm{g} \mathrm{g}^{-1}\right)$ of metal ion adsorbed at equilibrium and at time $\mathrm{t}$ respectively and $\mathrm{K}$ is the overall rate constant. Straight lines were obtained by plotting $\log \left(\mathrm{q}_{\mathrm{e}}-\mathrm{q}_{\mathrm{t}}\right)$ against $\mathrm{t}$, as shown in Figure 5. This indicates that copper ion sorption onto cynodon dactylon follows the first order kinetics. The correlation coefficients $\left(\mathrm{r}^{2}\right)$ given in Table 3 and 5 are greater than 0.98 , indicating that the model adequately describe the experimental data of metal bio sorption experiment. An examination of the effect of metal ion concentration from 10 to $60 \mathrm{mg} / \mathrm{L}$ on the rate constant $\left(\mathrm{K}_{\mathrm{ad}}\right)$ helps to describe the mechanism of removal taking place (Table 7). In cases of strict surface adsorption a variation of rate should be proportional to the power of concentration. However, when pore diffusion limits the adsorption process, the relationship between initial copper ion concentration and the rate of reaction will not be linear. It seems likely that pore diffusion limits the overall rate of copper ion adsorption ${ }^{26}$. Weber and Morris show that, in adsorption process, the contact time experimental results can be used to study the rate limiting step ${ }^{27,28}$. 


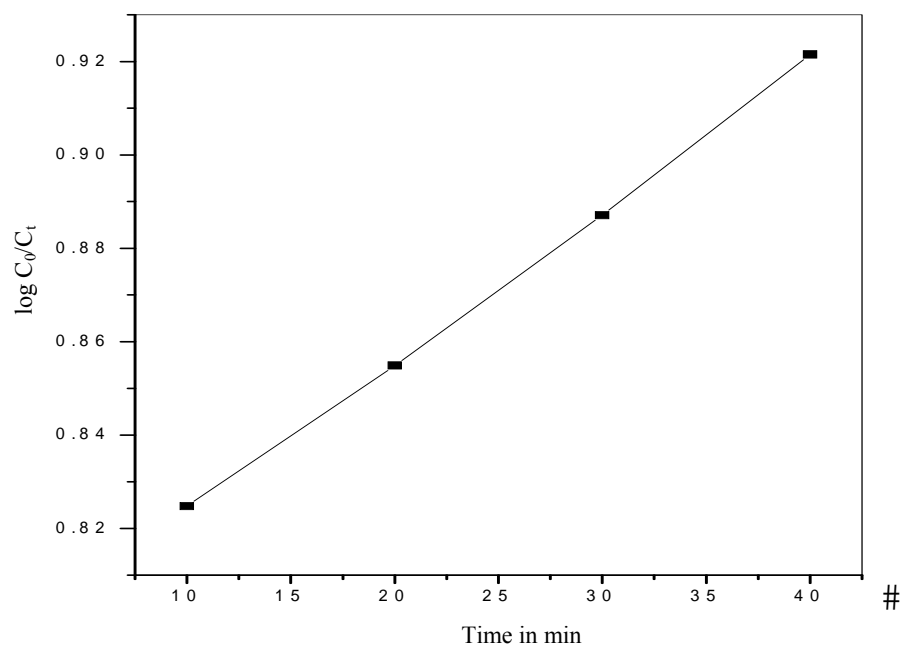

Figure 5. Natarajan Khalaf plot for the adsorption of copper ion by $\mathrm{CBC}[\mathrm{Cu}]=30 \mathrm{mg} / \mathrm{L}$; temp $=35^{\circ} \mathrm{C}$; contact time $=60 \mathrm{~min}$; adsorbent dose $=25 \mathrm{mg} / 50 \mathrm{~mL}$

\section{Intra particle diffusion study}

During the batch mode of operation, there was a possibility of transport of sorbate species into the pores of the sorbent, which is often the rate controlling step. The rate constants of intra particle diffusion $\left(\mathrm{K}_{\mathrm{id}}\right)$ at different copper ion concentrations were determined using the following equation ${ }^{29}$

$$
\mathrm{q}=\mathrm{K}_{\mathrm{id}} \mathrm{t}^{1 / 2}
$$

Where $q$ is the amount sorbed at time $t$ and $t^{1 / 2}$ is the square root of the time. The values of $K_{i d}$ were calculated from the slope of respective plot ( $q$ versus $t^{1 / 2}$ Figure 6 ) at later stages are given in Table 8. The dual nature of the curves was obtained due to the varying extent of sorption in the initial and final stages of adsorption. This can be attributed o the fact that in the initial stages, sorption was due to boundary layer diffusion effect, whereas, in the later stages (linear portion of the curve) was due to the intra particle diffusion was not only rate determining step, because it did not pass through the origin. This was further supported by calculating the intra particle diffusion coefficient (D) using the following equation ${ }^{30}$

$$
\mathrm{D}=0.03 \mathrm{r}^{2} / \mathrm{t}^{1 / 2}
$$

Where $\mathrm{r}^{2}(\mathrm{~cm})$ is the average radius of the sorbent particle and $t^{1 / 2}(\mathrm{~min})$ is the time for half of the adsorption. According to Michelson ${ }^{30}$, a D value of the order of $10^{-11} \mathrm{~cm}^{2} \mathrm{~S}^{-1}$ is indicative of intra particle diffusion as rate limiting step. It was concluded that both boundary layer and intra particle diffusion might be involved in this removal process.

\section{Thermodynamic evaluation of the process}

Thermodynamic parameters such as free energy of sorption $\left(\Delta \mathrm{G}^{0}\right)$, the heat of sorption $\left(\Delta \mathrm{H}^{0}\right)$ and standard entropy $\left(\Delta \mathrm{S}^{0}\right)$, changes during the sorption process were calculated using equations ${ }^{31,32}$.

$$
\mathrm{K}_{\mathrm{c}}=\mathrm{C}_{\wedge_{\mathrm{e}}} / \mathrm{C}_{\mathrm{e}}
$$

Where $\mathrm{K}_{\mathrm{c}}$ is the equilibrium constant and $\mathrm{C}_{\mathrm{e}_{\mathrm{e}}}$ and $\mathrm{C}_{\mathrm{e}}$ (both in $\mathrm{mg} / \mathrm{L}$ ) are the equilibrium concentrations for copper ions on the cynodon dactylon adsorbent and in the solution respectively. The $K_{c}$ values are used in equations (8) and (9) to determine $\Delta G^{0}, \Delta H^{0}$ and $\Delta S^{0}$.

$$
\Delta \mathrm{G}^{0}=-\mathrm{RT} \ln \mathrm{Kc}
$$

The $\mathrm{K}_{\mathrm{c}}$ may be expressed in terms of the $\Delta \mathrm{H}^{0}\left(\mathrm{~K} \mathrm{cal} \mathrm{mol}^{-1}\right)$ and $\Delta \mathrm{S}^{0}\left(\mathrm{cal} \mathrm{mol}^{1} \mathrm{~K}^{-1}\right)$ as a function of temperature. 


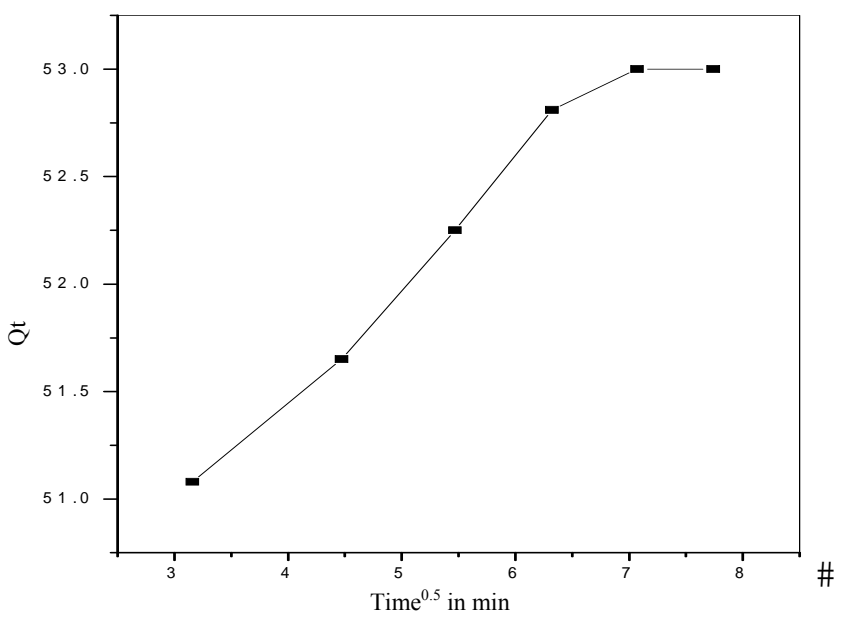

Figure 6. Intra-particle diffusion effect for the adsorption of copper ion by $\mathrm{CBC}[\mathrm{Cu}]=30 \mathrm{mg} / \mathrm{L}$; contact time $=60 \mathrm{~min}$; temp $=35^{\circ} \mathrm{C}$; adsorbent dose $=25 \mathrm{mg} / 50 \mathrm{~mL}$

$$
\ln \mathrm{Kc}=\Delta \mathrm{H}^{0} / \mathrm{RT}+\Delta \mathrm{S}^{0} / \mathrm{R}
$$

The values of $\Delta \mathrm{H}^{0}$ and $\Delta \mathrm{S}^{0}$ can be calculated from the slope and intercept of a plot of $\ln$ Kc versus 1/T, Figure 7 and in Table 6 the values of these parameters are recorded. The negative values of $\Delta \mathrm{G}^{0}$ indicate the spontaneous nature of the process and more negative value with increase of temperature favors the sorption process. The positive values of $\Delta \mathrm{H}^{0}$ indicated that the sorption process was endothermic in nature and the positive values of $\Delta \mathrm{S}^{0}$ indicate that the increased disorder and randomness at the solid solution interface of with adsorbent Cynodon dactylon ${ }^{11,19,33}$. From the results, we could make out that more efficient physisorption.

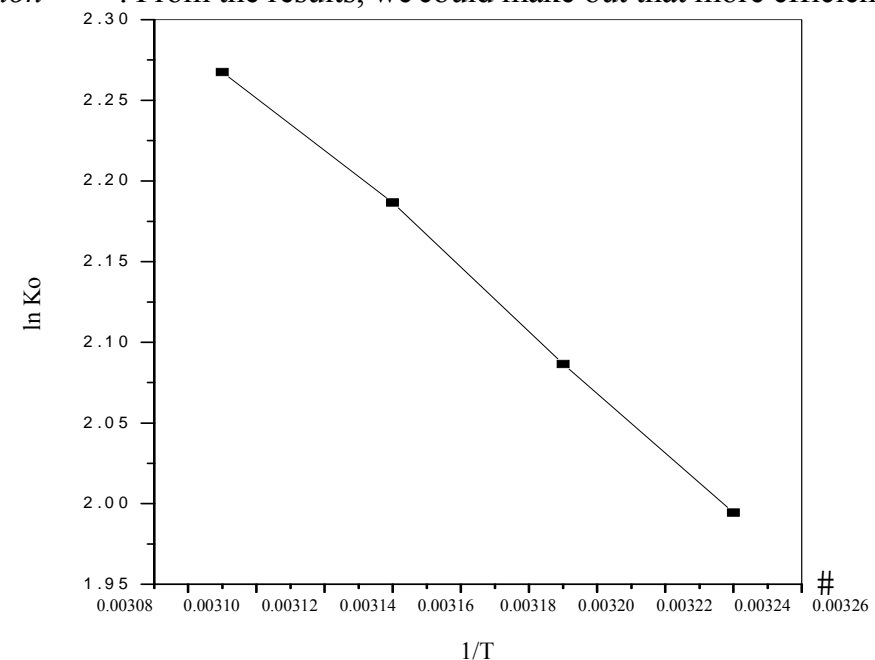

Figure 7. Vant $\mathrm{H}$ offs plot for the adsorption of copper ion by $\mathrm{CBC}[\mathrm{Cu}]=30 \mathrm{mg} / \mathrm{L}$; Adsorbent dose $=25 \mathrm{mg} / 50 \mathrm{~mL}$; Contect time $=60 \mathrm{~min}$

\section{Effect of $p H$}

The experiments carried out at different $\mathrm{pH}$ shows that there was a change in the percent removal of copper ion over the entire $\mathrm{pH}$ range of 3 to 10, shown in Figure 8. This indicates the strong force of interaction between the copper ion and the activated cynodon dactylon that, either $\mathrm{H}^{+}$or 
$\mathrm{OH}^{-}$ions could influence the adsorption capacity. Here the interaction is more at $\mathrm{pH} 5.5$, the competence of acidic $\mathrm{H}^{+}$ion with copper cation for the sorption sites. The percentage of sorption increased at the above $\mathrm{pH}$ value is due to the presence of ionic $\mathrm{COOH}$ groups. The adsorption of copper ion on the activated Cynodon dactylon does involve ion exchange mechanism. Due to the adsorption of copper ion through ion exchange mechanism by the activated Cynodon dactylon, there should be an influence on the copper ion adsorption while varying the $\mathrm{pH}$. This observation is in line with the type I and II isotherm shown in Figure 1 and Figure 2. The positive $\Delta \mathrm{H}^{0}$ value obtained, which indicates irreversible adsorption probably due to polar interaction ${ }^{34,35}$. The other important factors, which might contribute to the high adsorption of copper ions with increased $\mathrm{pH}$, is the $\mathrm{pH}_{\mathrm{Zpc}}$ of Cynodon dactylon. At any $\mathrm{pH}$ below $\mathrm{pH}_{\mathrm{Zpc}}$, the surface of metal oxides / oxy hydroxides is positively charged and at $\mathrm{pH}$ above $\mathrm{pH}_{\mathrm{Zpc}}$ the surface is negative. When the solution $\mathrm{pH}$ exceeded $\mathrm{pH}_{\mathrm{Zpc}}$, the copper species are more easily attracted by the negatively charged surface of adsorbent Cynodon dactylon, favoring accumulation of copper species on the surface and thus promoting adsorption ${ }^{36,37}$.

Table 6. Equilibrium constant and thermodynamic parameters for the adsorption of Copper ions by activated $\mathrm{CBC}$

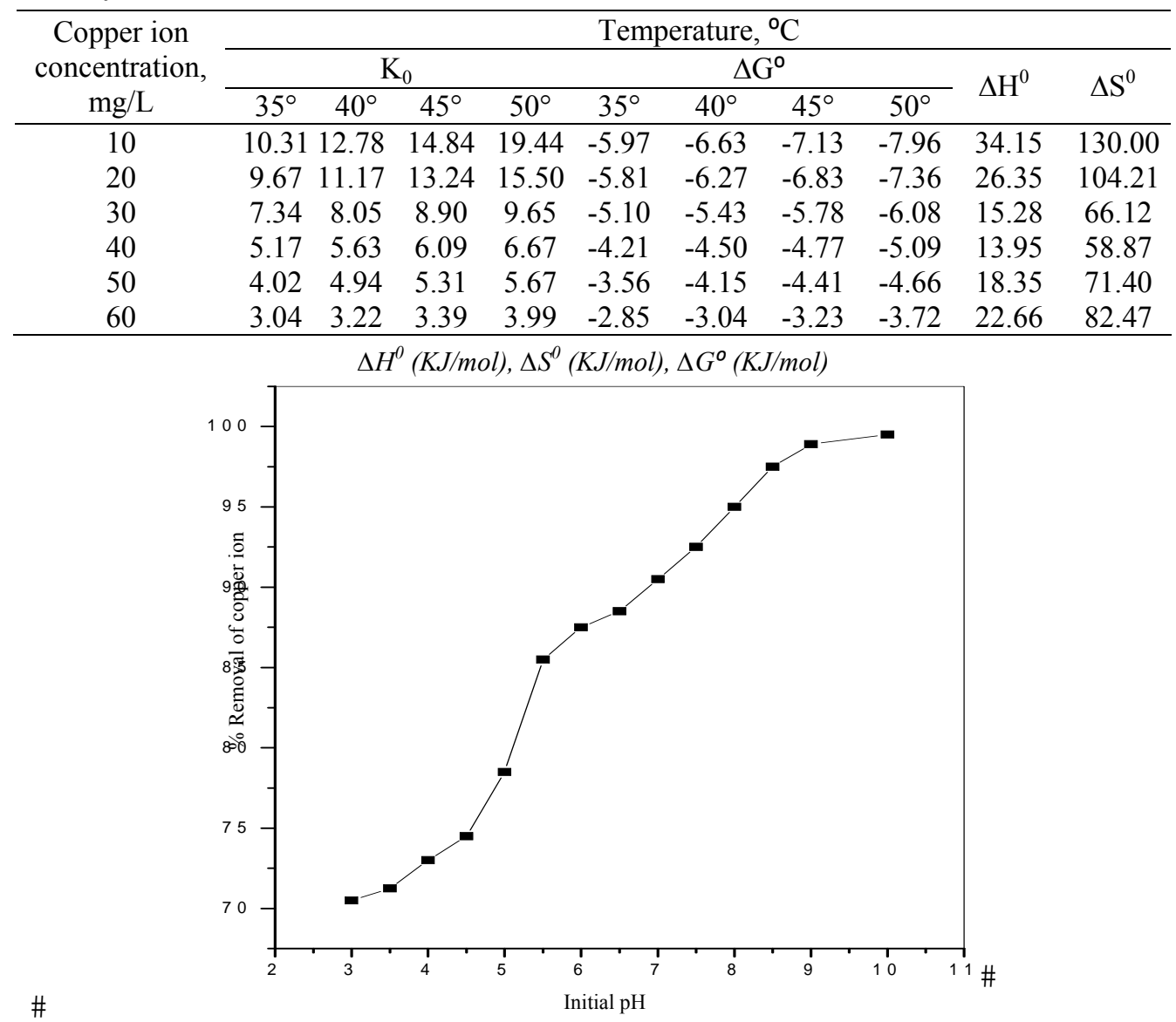

Figure 8. Effect of $\mathrm{pH}$ on the adsorption of copper ion $\mathrm{CBC}[\mathrm{Cu}]=30 \mathrm{mg} / \mathrm{L}$; Contact time $=60 \mathrm{~min}$; Adsorbent dise $=25 \mathrm{mg} / 50 \mathrm{~mL}$; Temp $=35^{\circ} \mathrm{C}$ 
Table 7. Rate constants for the adsorption of copper ion $\left(10^{3} \mathrm{k}_{\mathrm{ad}}, \mathrm{min}^{-1}\right)$ and the constant for forward $\left(10^{3} \mathrm{k}_{1}, \mathrm{~min}^{-1}\right)$ and reverse $\left(10^{3} \mathrm{k}_{2}, \min ^{-1}\right)$ process

\begin{tabular}{ccccccccccccc}
\hline \multirow{2}{*}{$\begin{array}{c}\text { Copper ion } \\
\text { concentration } \\
\text { mg/L }\end{array}$} & \multicolumn{10}{c}{$\mathrm{K}_{\mathrm{ad}}$} & \multicolumn{10}{c}{ Temperature, ${ }^{\circ} \mathrm{C}$} \\
\cline { 2 - 13 } & $35^{\circ}$ & $40^{\circ}$ & $45^{\circ}$ & $50^{\circ}$ & \multicolumn{3}{c}{$35^{\circ}$} & $40^{\circ}$ & $45^{\circ}$ & $50^{\circ}$ \\
\hline 10 & 10.93 & 11.42 & 11.92 & 12.35 & 9.96 & 0.97 & 10.59 & 0.83 & 11.17 & 0.75 & 11.74 & 0.61 \\
20 & 10.01 & 11.37 & 11.65 & 12.08 & 9.07 & 0.94 & 10.38 & 0.93 & 10.83 & 0.82 & 11.35 & 0.73 \\
30 & 8.75 & 8.96 & 9.13 & 9.37 & 7.71 & 1.04 & 7.97 & 0.99 & 8.21 & 0.92 & 8.49 & 0.88 \\
40 & 5.73 & 6.43 & 6.98 & 7.42 & 4.81 & 0.92 & 5.46 & 0.97 & 6.02 & 0.96 & 6.45 & 0.97 \\
50 & 4.92 & 5.75 & 6.52 & 7.23 & 3.94 & 0.98 & 4.78 & 0.97 & 5.49 & 1.03 & 6.15 & 1.08 \\
60 & 4.61 & 4.92 & 5.28 & 5.64 & 3.47 & 1.14 & 3.76 & 1.16 & 4.08 & 1.20 & 4.51 & 1.13 \\
\hline
\end{tabular}

Table 8. Intra particle diffusion $\left(\mathrm{K}_{\mathrm{p}}\right)$ for the adsorption of copper ion by $\mathrm{CBC}$

\begin{tabular}{cc}
\hline Copper ion concentration, $\mathrm{mg} / \mathrm{L}$ & $\mathrm{K}_{\mathrm{p}}$ \\
\hline 10 & 0.223 \\
20 & 0.341 \\
30 & 0.458 \\
40 & 0.576 \\
50 & 0.694 \\
60 & 0.819 \\
\hline
\end{tabular}

\section{Effect of calcium and chloride ion}

The contaminated water contains several other ions (both cations and anions), which can affect the adsorption of heavy metals. This present study results discussed that while effect of calcium and chloride ion would affect the adsorption of copper ion or not. A typical water sample containing $\mathrm{Cl}^{-}$and $\mathrm{Ca}^{2+}$ ions were doped with known quantities of copper ions and they were used as the stimulated water matrix for adsorption. A fixed amount of Cynodon dactylon was dispersed in this matrix containing copper ions. The results are presented in Figure 9. The concentration of other ions, however, marginally decreased after adsorption. (Within $10 \%$ initial concentration). At higher concentration level of interfering ions may however, adversely affect the absorption capacity of Cynodon dactylon. Adsorption of different heavy metal from a stimulated water matrix containing a high back ground level of different ions is being carried out to assess its future applicability to removal of toxic heavy metals from industrial effluents ${ }^{37-39}$.

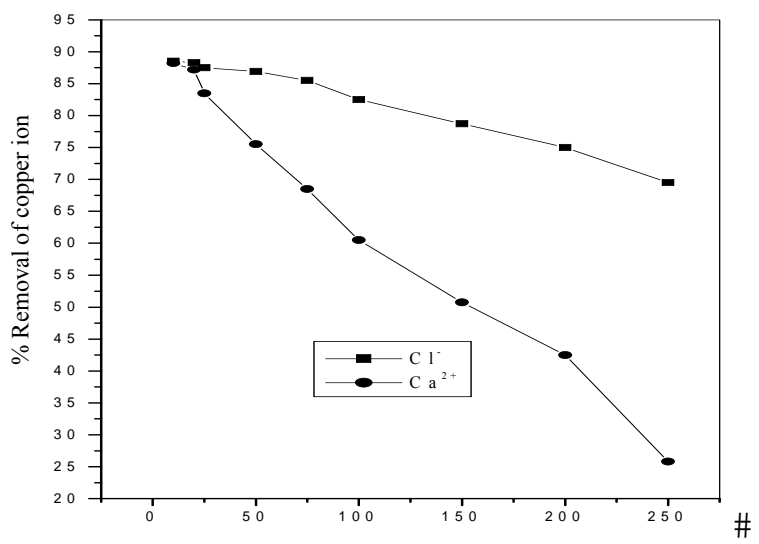

Figure 9. Effect other ions on the removal of copper ion by $\mathrm{CBC}[\mathrm{Cu}]=30 \mathrm{mg} / \mathrm{L}$; Adsorbent dose $=25 \mathrm{mg} / 50 \mathrm{~mL}$; temp $=35^{\circ} \mathrm{C}$ contact time $=60 \mathrm{mg} / \mathrm{L}$ 


\section{Desorption studies}

The nature of adsorption, recycling of the spent adsorbent and the copper ion was studied by using desorption studies. If neutral $\mathrm{pH}$ water was taken, the adsorbed copper ion can be desorbed, and then the binding of the copper ion of the adsorbent is by weak bonds. During ion exchange, the adsorption between adsorbent and sulphuric acid or alkaline water desorp the copper ion. If chemisorptions taken place organic acids like acetic acid can desorp the copper ion, then the metal ion has held by the adsorbent. Hydrochloric acid is a better reagent for desorption studies compared to various reagents used for desorption studies, because we could get more than $76 \%$ removal of adsorbed copper ion. The rate of sorption was highly $\mathrm{pH}$ dependent. The desorption of copper ion by mineral acids and the alkaline medium indicates that the copper ion was adsorbed onto activated CBC through the physisorption mechanisms ${ }^{19-21,33}$.

\section{Evidences for adsorption}

FT- IR spectral studies

FT - IR spectra for the activated Cynodon dactylon before and after adsorption of copper ion have been recorded a representation spectrum is shown in Figures 10a and 10b. From the figure, it could be seen that, the peak position is not changed but the slight reduction of stretching vibration of adsorption bonds takes place. This figure indicates that the adsorption of copper ion on the activated Cynodon dactylon by physical forces not by chemical combination.

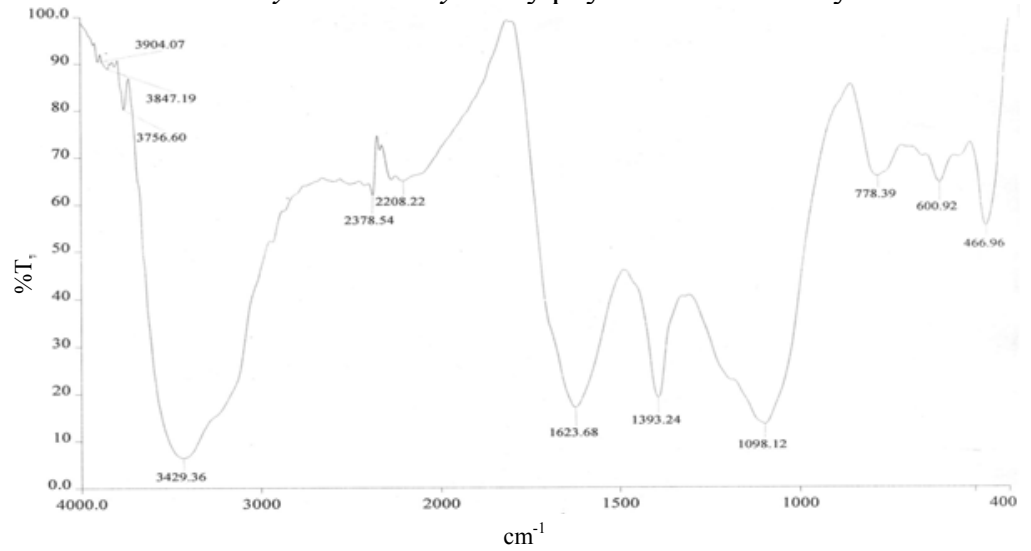

Figure 10a. FT - IR Spectra for raw Cynodon dactylon carbon

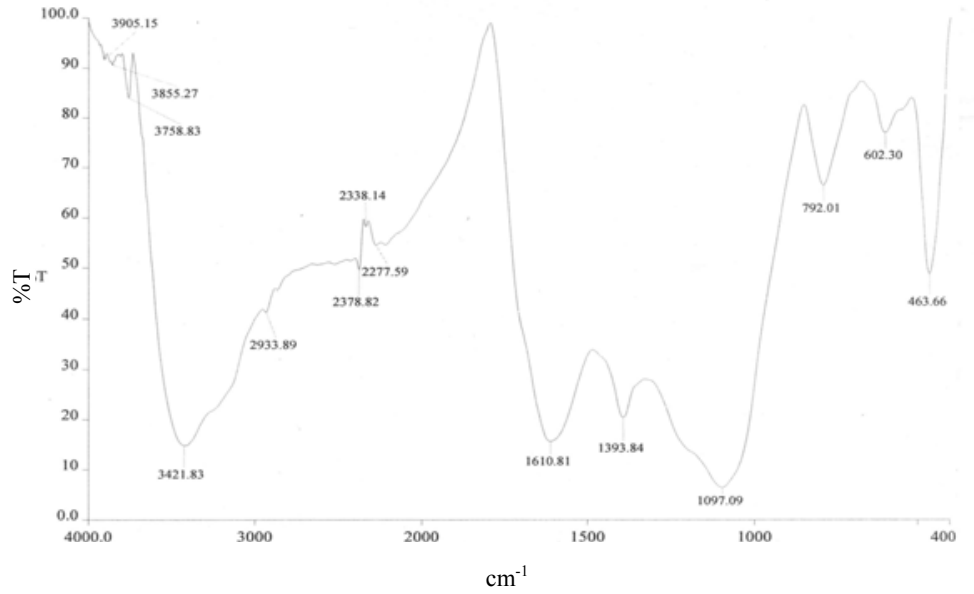

Figure 10b. FT - IR Spectra for the adsorption of copper ion onto CBC 


\section{XRD spectral studies}

A representative XRD pattern of the activated Cynodon dactylon and copper ion adsorbed Cynodon dactylon is shown in Figures $11 \mathrm{a}$ and $11 \mathrm{~b}$. The intense main peak shows the presence of highly organized crystalline structure of raw activated carbon, after the adsorption of copper ion, the intensity of the highly organized peaks is slightly disappeared. This has attributed to the adsorption of copper ion on the upper layer of the crystalline structure of the carbon surface by means of physisorption rather than chemisorptions.

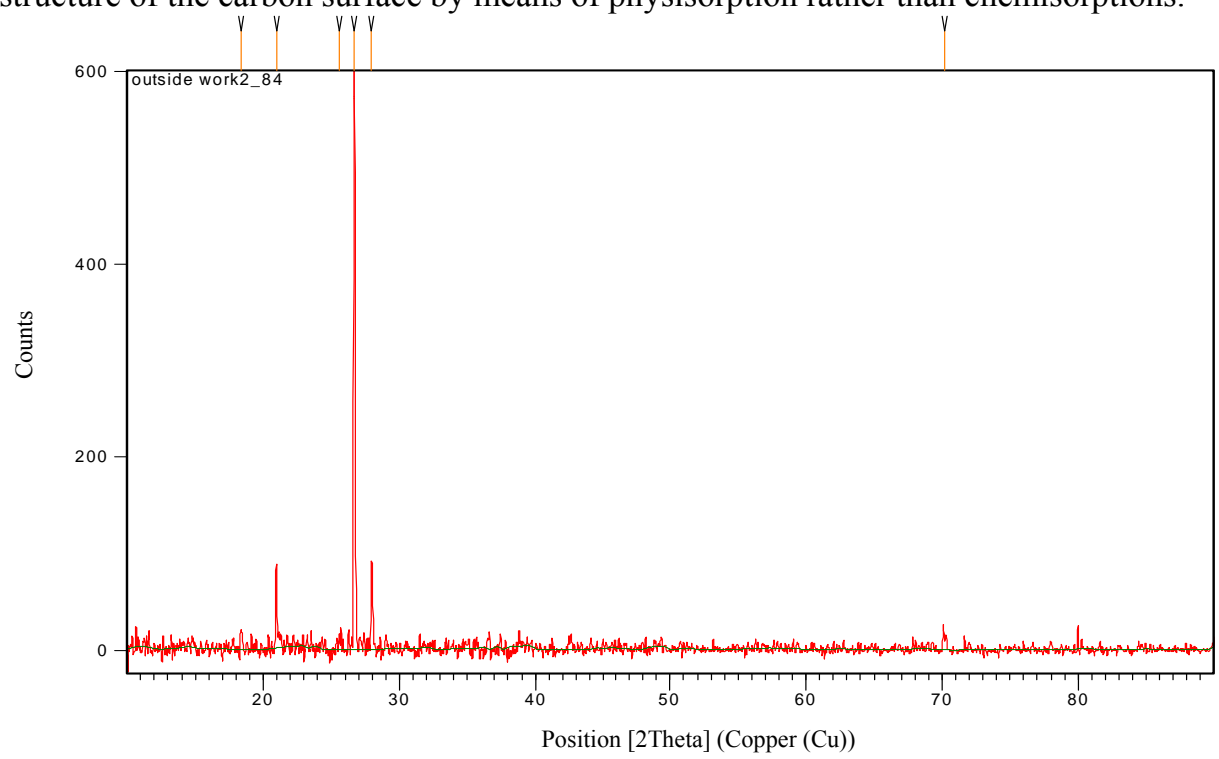

Figure 11a. XRD spectra for raw cynodon dactylon

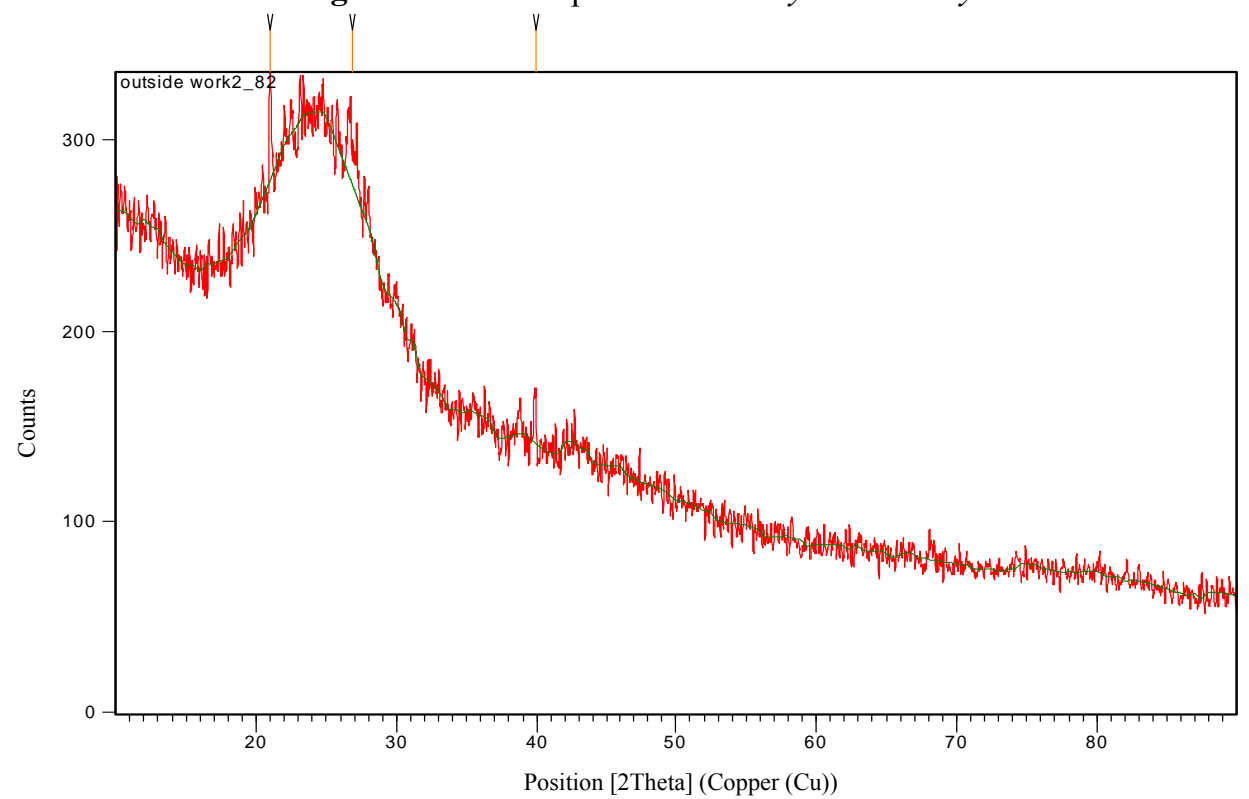

Figure 11b. XRD spectra for the adsorption of copper ion onto CBC 


\section{SEM images}

The SEM images of raw activated carbon and a representative image is given in Figures 12a and $12 \mathrm{~b}$. The bright spots shows the presence of tiny holes on the crystalline of raw activated carbon, after treatment with copper ions the bright spots became black shows the adsorption of the copper ion on the surface of the activated Cynodon dactylon ${ }^{38,39}$.

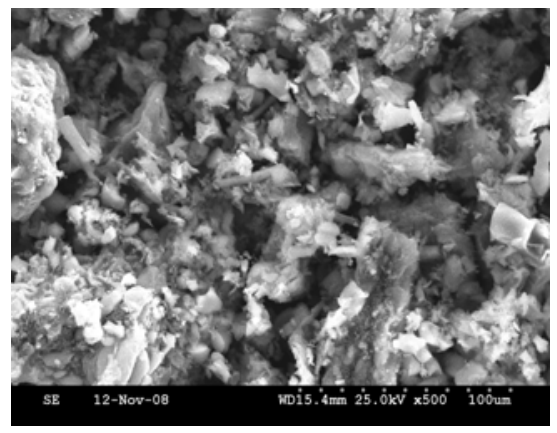

Figure 12a. SEM images for Raw Cynodon dactylon

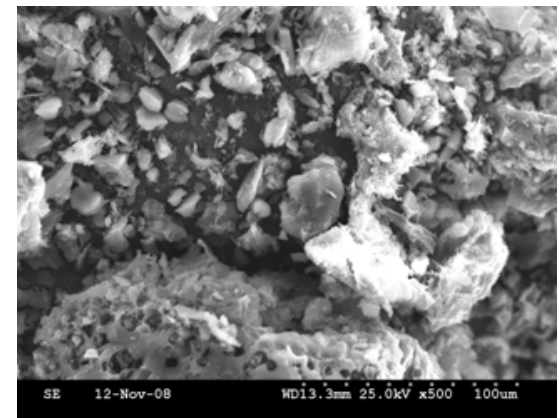

Figure 12b. SEM images for the adsorption of copper ion onto CBC

\section{Conclusion}

Activated Cynodon dactylon has been found to be an economically viable and potential bio sorbent for the removal of copper ion. Sorption of copper ion onto activated Cynodon dactylon, this present work has indicated that the sorbent provides an alternative or adjacent to conventional methods employed to control the level of copper pollution. From the thermodynamic studies, the value of $\Delta \mathrm{H}^{0}$ and $\Delta \mathrm{S}^{0}$ could be obtained from the slope and intercept of the relationship between $\Delta \mathrm{G}^{0}$ and reaction temperature. The negative values of $\Delta \mathrm{G}^{0}$ indicate the spontaneous nature of adsorption with a high preference of copper ion onto Cynodon dactylon. The values of $\Delta \mathrm{H}^{0}$ was positive, indicated that the adsorption reaction was endothermic. The positive values of $\Delta \mathrm{S}^{0}$ shows that increasing randomness at the solid-liquid interface during the adsorption of copper ion on Cynodon dactylon. The fitness of the sorption data into Langmuir isotherm confirmed that the monolayer adsorption. The best correlation coefficient was obtained using the first order kinetic model indicates that copper ion removal process followed the first order rate expression. Mass transfer from sorbate to sorbent was rapid enough. The kinetics of adsorption seems to be controlled by diffusion of copper ions into the micropores. Desorption studies was also carried out and found that complete desorption of copper ion takes place at $\mathrm{pH} 10$. Desorption of copper ion in mineral acid suggest that the adsorption of copper ion on Cynodon dactylon involved chemisorptions as well as physisorption. The dimensionless separation factor $\left(\mathrm{R}_{\mathrm{L}}\right)$ showed that the activated Cynodon dactylon could be used for the removal of copper ion from aqueous solution.

\section{Acknowledgment}

The author acknowledges sincere thanks to the Correspondent, the Principal, S.T.E.T. Women's College, Mannargudi for carrying out this research work successfully.

\section{References}

1. Omgbu J A and Kokogbo M A, Environ Int., 1993, 19, 611-612.

2. Yusuf A A, Arowolo T A and Bombose O, Food Chem Toxicol., 2003, 41(3), 375-378. 
3. Ajibola V O and Ozigis I, J Chem Soc Nigeria, 2005, 30, 62-66.

4. Inglezakis V J, Loizidou M D and Grigoropoulou H P, J Colloid Interface Sci., 2003, 49, 261.

5. $\quad$ Applegate L E, Chem Eng., 1984, 64. 91.

6. Sengupta A K and Clifford D, Environ Sci Technol., 1986, 20, 149.

7. Geselbarcht J, Micro Filtration/Reverse Osmosis, Pilot Trials for Livermore, California, Advanced water Reclamation in, Water Reuse, Conference Proceedings, AWWA, 1996, p.187.

8. Schnoor J L, Remediation of Metals-Contaminated Soils and Groundwater Phytoremediation TE-97-01, Ground-water Remediation Technologies Analysis Center, Pittsburgh, 1997.

9. Huang C P and Blankenship D W, Water Res., 1984. 18(1), 37-46.

10. Jia Y F and Thomas K K, Langmuir, 2002, 18, 470-478.

11. Namasivayam C, Muniasamy N, Gayathri K, Rani M and Renganathan K, Biores Technol., 1996, 57(1), 37-43.

12. Namasivayam C and Yamuna, R T, Environ Pollut., 1995, 89, 1-7.

13. Senthilkumar S, Varadharajan P R, Porkodi K and Subburaam C V, J Colloid Interface Sci., 2005, 284, 78-82.

14. Namasivayam C and Kanchana N, Chemsphere, 1992, 25, 1691-1705.

15. Langmuir I, J Am Chem Soc., 1918, 40, 1361.

16. Krishna D G and Bhattacharya G, Appl Clay Sci., 2002, 20, 295.

17. Arivoli S, Viji Jain M and Rajachandrasekar T, Mat Sci Res India, 2006, 3, 241-250.

18. Bhattacharya A K, Manda S N and Das S K, Chem Eng J., 2006, 123, 43-51.

19. Arivoli S and Hema M, Intern J Phys Sci., 2007, 2, 10-17.

20. Arivoli S, Venkatraman B R, Rajachandrasekar T and Hema M, Res J Chem Environ., 2007, 17, 70.

21. Sudha R, Kalpana K, Rajachandrasekar T and Arivoli S, E. J Chem., 2007, 4(2), 238-254.

22. Hasany S M, Saeed M .M and Ahmed M J, Radioanal Nucl Chem., 2002, 252, 477-484.

23. Badmus M A O, Audu T O K and Anyata B U, Korean J Chem Eng., 2007, 24, 246-252.

24. Bhattacharya A K and Venkobar C, J Env Eng., 1984, 110(1), 110-112.

25. Soner A H, Altundoger S, Tumen F and Bidik M, Waste Manage., 2002, 22, 357-363.

26. Ozacar M and Sengil I A, Bioresour Technol., 2005, 96, 791-795.

27. Weber W J, Edited by Faust S D and Hunter J V, Wiley, New York, 1967.

28. Pollard S J T, Fowler G D, Sollars C J and Perry R, Sci Total Environ., 1992, 116, 31-52.

29. Weber W J, Morris J C and San J, Eng Div Proc Anal Soc Civil Eng., 1963, 89, SA2.

30. Michelseon L D, Gideon P G, Pace E G and Kutsal L, US. Dept. Industry, Office of the water Research and Technology, Bull.No.1975, p.74.

31. Ho Y S, Water Res., 2003, 37, 2323-2330.

32. Singh K, Singh A K and Hasan S H, Bioresource Technol., 2006, 97, 994-1001.

33. Sreedhar M K and Anirudhan T S, Indian J Environ Protect., 1999, 19, 8.

34. Sivaraj R, Namasivayam C and Kadirvelu K, Waste Manage., 2001, 21, 105.

35. Stephen Inbaraj B and Sulochana N, Indian J Chem Technol., 2002, 9, 201.

36. Yupeng Guo, Jingzhu zhao, Huizhang, Shaofeng Yang, Zichen Wang and Hongding X U, Dyes Pigments, 2005, 66, 123.

37. Nigamananda Das and Ranjit Kumar Jana, J Colloid Interface Sci., 2006, 293, 253.

38. Venkata Mohan S, Krishna Mohan S and Karthikeyan J, J Sci Ind Res., 2001, 60, 410-415.

39. Renmin Gong, Youbin Jin, Fayang Chen, Jian Chen and Zhil Liu, J Hazardous Mat., 2006, 137(2), 865-870. 


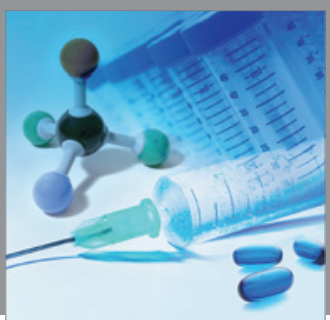

International Journal of

Medicinal Chemistry

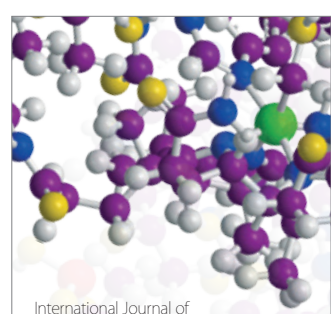

Carbohydrate Chemistry

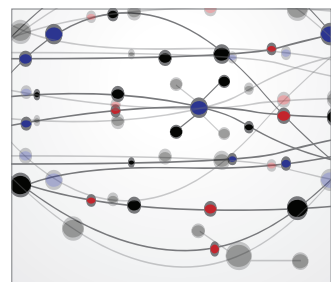

The Scientific World Journal
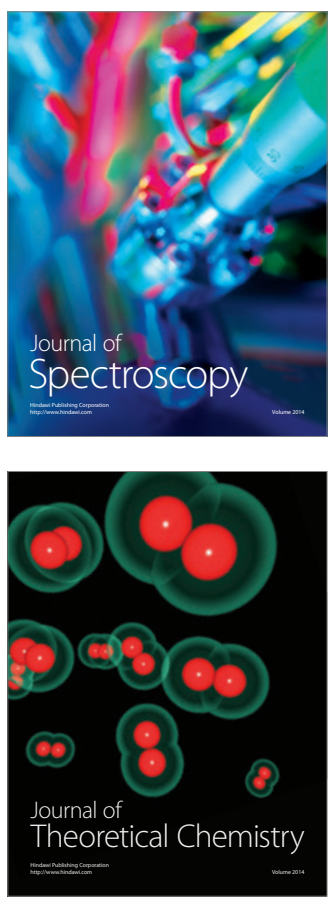
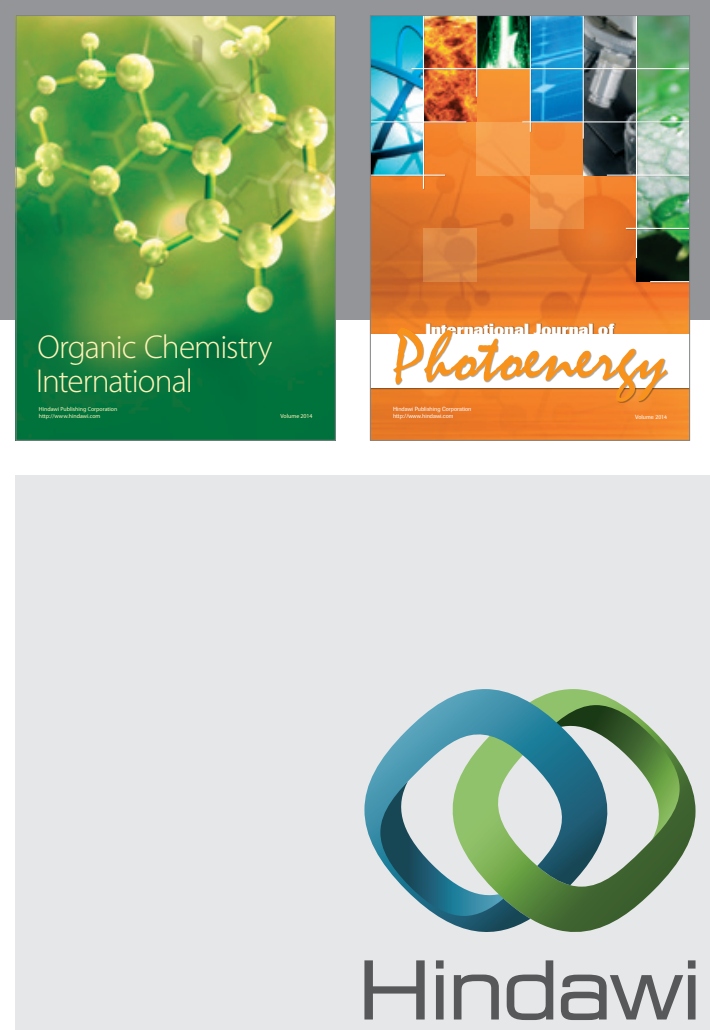

Submit your manuscripts at

http://www.hindawi.com
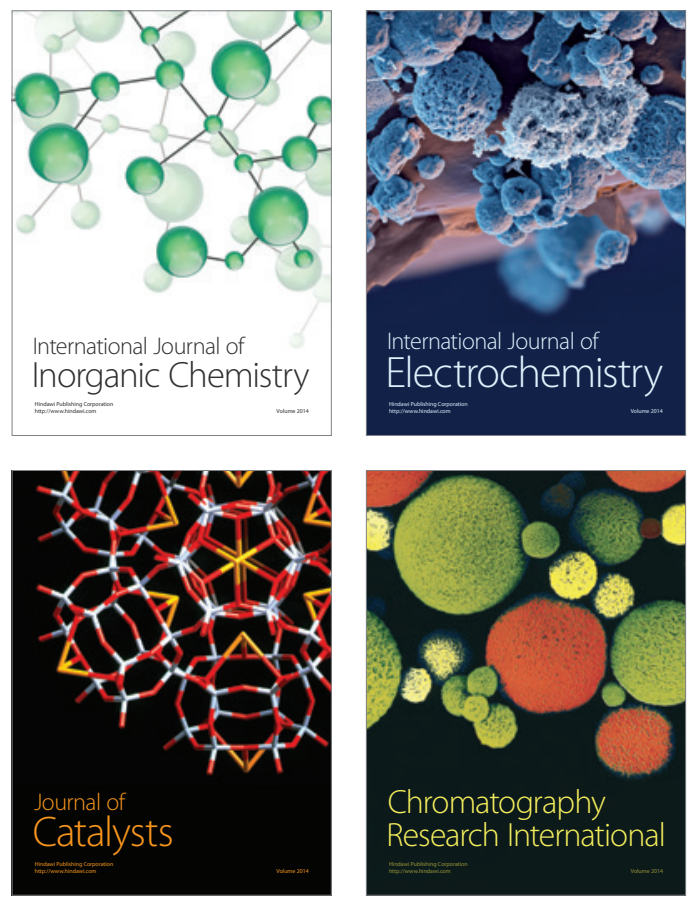
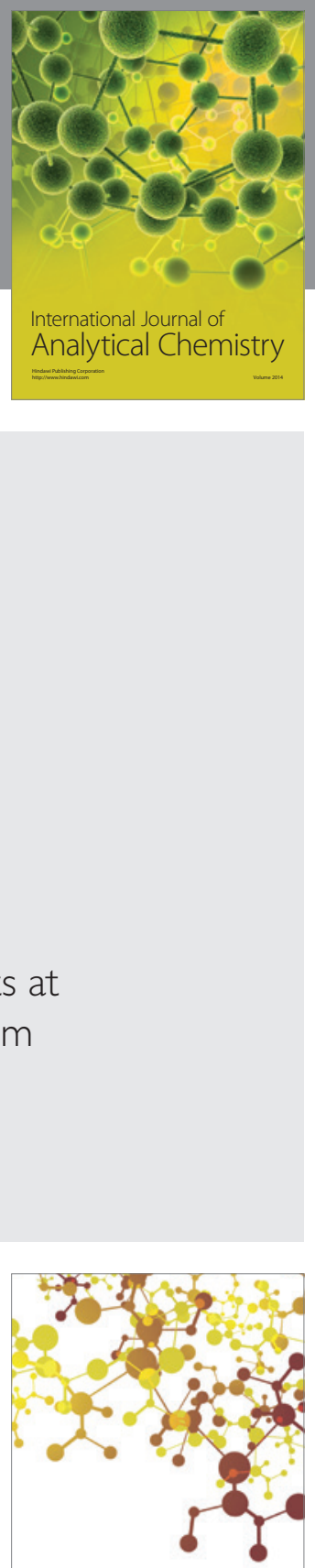

Journal of

Applied Chemistry
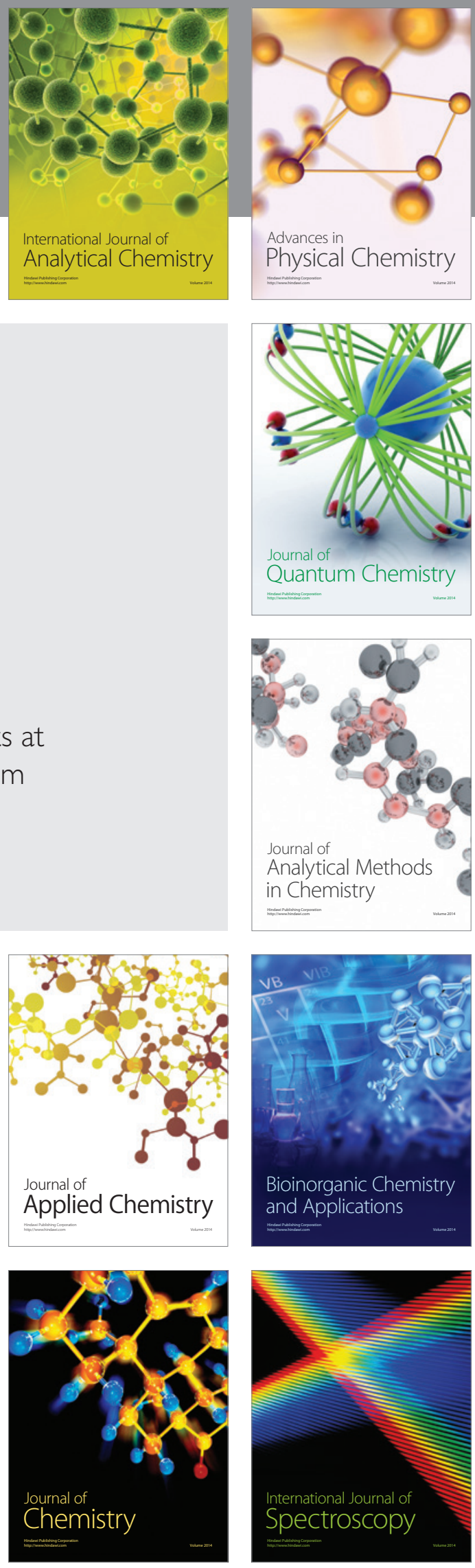